\title{
Erratum to: Large quantity discrimination by North Island robins (Petroica longipes)
}

\author{
Alexis Garland $\cdot$ Jason Low $\cdot$ Kevin C. Burns
}

(C) Springer-Verlag 2012

\section{Erratum to: Anim Cogn}

DOI 10.1007/s10071-012-0537-3

In the original publication, the labels of x-axes in Fig. 4 were published incorrectly. The correct Fig. 4 is produced in the following page.

The online version of the original article can be found under doi:10.1007/s10071-012-0537-3.

\author{
A. Garland $(\bowtie) \cdot$ J. Low \\ School of Psychology, Victoria University of Wellington, \\ P.O. Box 600, Wellington 6012, New Zealand \\ e-mail: Alexis.Garland@vuw.ac.nz \\ K. C. Burns \\ School of Biological Sciences, Victoria University \\ of Wellington, Wellington, New Zealand
}


(a)

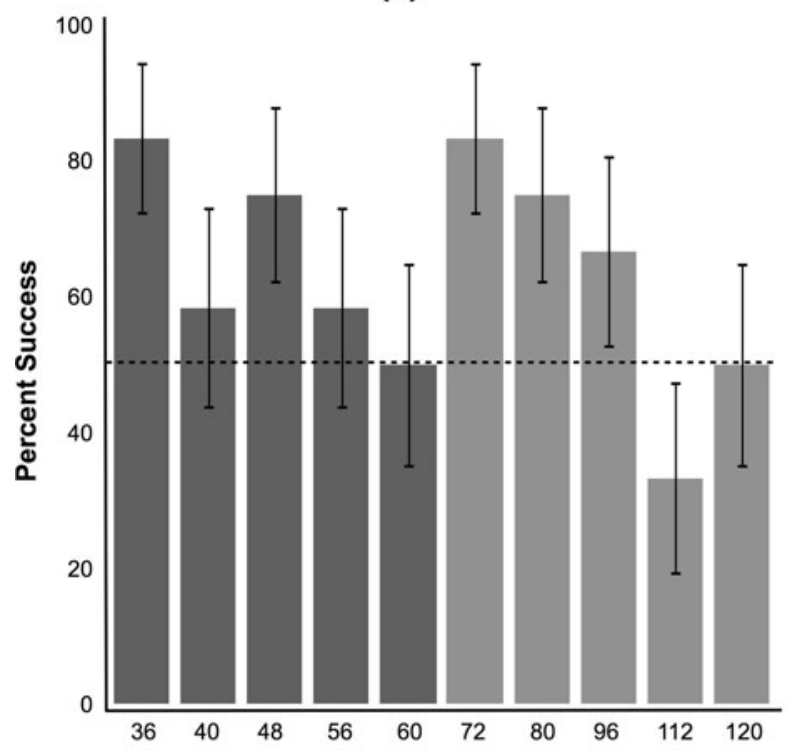

Total Number of Worms (b)

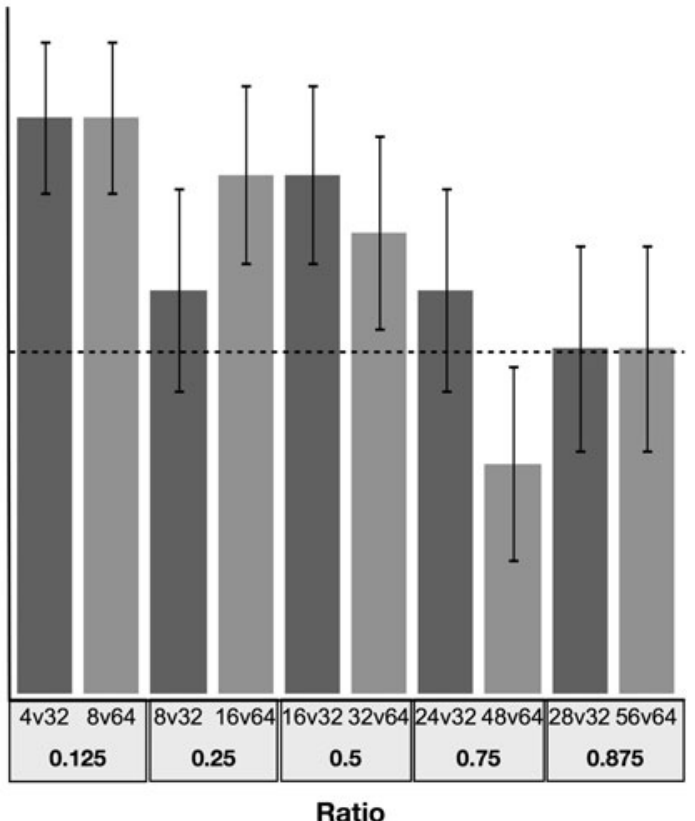

Fig. 4 Percentage of correct trials as a function of a ratio and $\mathbf{b}$ total number of worms (combined set size), for whole set presentation of comparisons containing up to 120 total prey items $(N=12)$ 